This item was submitted to Loughborough's Research Repository by the author.

Items in Figshare are protected by copyright, with all rights reserved, unless otherwise indicated.

\title{
Are we fit yet? English adolescent girls' experiences of health and fitness apps
}

PLEASE CITE THE PUBLISHED VERSION

http://dx.doi.org/10.1080/14461242.2016.1196599

\section{PUBLISHER}

Taylor and Francis (@ 2016 Informa UK Limited)

VERSION

AM (Accepted Manuscript)

\section{PUBLISHER STATEMENT}

This work is made available according to the conditions of the Creative Commons Attribution-NonCommercialNoDerivatives 4.0 International (CC BY-NC-ND 4.0) licence. Full details of this licence are available at: https://creativecommons.org/licenses/by-nc-nd/4.0/

\section{LICENCE}

CC BY-NC-ND 4.0

\section{REPOSITORY RECORD}

Depper, Annaleise, and P. David Howe. 2019. "Are We Fit Yet? English Adolescent Girls' Experiences of Health and Fitness Apps”. figshare. https://hdl.handle.net/2134/21914. 


\title{
Are we fit yet? English adolescent girls' experiences of health and fitness apps
}

Word count: 7469

\begin{abstract}
In recent years, society has witnessed a proliferation of digital technologies facilitate new ways to monitor young people's health. This paper explores a group of English adolescent girls' understandings of 'health' promoted by health and fitness related technologies. Five focus group meetings with the same eight girls, aged between fourteen and seventeen, were conducted to explore their experiences of using health and fitness apps. The girls' understandings of the digitised body are examined through a Foucauldian lens, with particular attention to conceptualisations of bio-power and technologies of the self. The data reveals how the girls negotiated, and at times critiqued, the multiple health discourses that are manifest through digital health technologies and performative health culture. The results emphasise that individual-based applications (apps) remove the social and interactive elements of physical activity valued by the girls. This research highlights the possibilities digital technologies provide for health promotion, yet also illuminates the limitations of these technologies if used uncritically and inappropriately.
\end{abstract}

Keywords: adolescent girls; apps; body; digital health; self-tracking; surveillance

\section{Introduction}

In this article we examine the views of a group of Sports Leaders, within an English state grammar school for girls, around engaging with health and fitness related apps and wearable technologies. We investigate the socio-cultural implications of utilising these devices upon their embodied health and their broader understanding of what it means to be ‘healthy’. Our research illustrates how a group of adolescent girls valued the social possibilities of engaging in physical activity, whilst criticised digital technologies for removing the interactive elements of traditional sport and for promoting narrow health ideals. 
In recent years, digital technologies related to health and fitness promotion have been emphasised as a technical solution to adolescents’ sedentary lifestyles (Sport England, 2015). Due to the ubiquity of interactive technologies within adolescents’ lives, 'apps' (specialised programs downloadable to mobile devices) have particularly resonated with young individuals (Ofcom, 2011). Over the past decade, the numerous readily available health and fitness technologies have arguably served a Western agenda to combat the so-called 'obesity epidemic' (Rich \& Miah, 2014), which has been the subject of academic dispute over its exaggeration and uncertainty (see Rich, 2011a). Indeed, digital devices contradict with government policy rhetoric that strives for a broader approach to reducing health disparities, as opposed to “focusing on individuals' specific health-related behaviours” (Lupton, 2015, p. 176).

In schools, digital health technologies have begun to be employed to promote physical activity amongst young people (Millington, 2009). Apps and wearable technologies function as pedagogical devices, facilitating an interactive space through which young people can learn how to value a desirable body in the pursuit of functional health (Rich \& Miah, 2014). As adolescents are encouraged to monitor and regulate their bodies, digital health technologies are arguably intrusive methods within the existing performative spaces of schools to serve wider societal health intervention. According to Evans, Rich, and Holroyd (2004), these body performance and perfection codes unjustly place "moral obligation and blame on individuals for their health/ problems” (p. 139). This neoliberal, ‘ideology of healthism’ pervades the lives of adolescents beyond schooling, as digital health technologies expand the parameters of surveillance upon the young body.

This paper begins with a review of academic literature that examines digital health technologies through notions of embodiment and subjectivity. At the forefront of 
this paper is this concept of embodiment and specific attention is given to how these notions inform our understanding of the embodied identities of both the participants and the focus group facilitator. We then explore Foucault's conceptualisation of bio-power in relation to understandings of the digitised, 'healthy' body. Subsequently, we examine digital health within popular pedagogical spaces, as they extend the boundaries through which adolescents can engage in self-monitoring to conform to culturally and socially acceptable body ‘ideals'.

\section{Situating embodied subjectivities}

With the growing commodification and privatisation of digital health technologies, health and fitness apps have the potential for "even more intense forms of surveillance, normalisation and potential 'Othering' of students whose data do not conform to set expectations” (Lupton, 2015, p. 128). It is important to consider the implications of these limited health discourses upon adolescents' embodied practices, subjectivities and discursive understandings of health. As McEvilly, Atencio, Verheul, and Jess (2013) emphasise, health discourses significantly influence “children's sense of self, which is directly linked with being physical and embodied” (p. 733).

Specifically, this research engages with the ways in which a group of female Sports Leaders subjectively negotiated the multiple discourses of 'health' within digital health technologies. Girls at this English grammar school were awarded the status of Sports Leaders by the Head of the Physical Education (PE) Department for taking on various responsibilities at the school, such as; assisting at sports related school events, being the captain of a sports team, umpiring sports fixtures and being positive sporting role models to other girls. We are reflexive that the embodiment of both the participants and the focus group facilitator was inextricably linked to the data collection process; this particular group of white, middle-class girls had an embodied sense of self as 
'sporty' individuals, while the girls subjectively interpreted and related to the facilitator's body as young, white and also ‘sporty'. For example, the girls collectively referred to individuals who might be considered as inactive or 'obese' as distinctly 'other' to those present in the focus group. We have embraced this importance of acknowledging the self as part of the subjectivities within the data collection, analysis and research writing at "every stage of the research” (Guillemin \& Gillam, 2004, p. 274).

\section{Foucault and the discursive construction of the digitised 'healthy' body}

The work of Foucault around discourse, bio-power and normalisation has received extensive attention across digital and health sociology. Digital health technologies have intensified the imperative to be healthy within modern society, which Foucault (1984) critiques, is "the duty of each and objective for all" (p. 277). Normalisation as a form of bio-power remains prevalent to understanding rising concerns over the so-called 'obesity epidemic' and has given rise to moral imperatives to be healthy, virtuous biocitizens (Harwood, 2009). According to Foucault (1978), through “continuous regulatory and corrective mechanisms” (p. 144) within society, monitoring is used to normalise individuals into docile bodies. Foucault refers to Jeremy Bentham’s “plan for the panopticon as the paradigm of a disciplinary technology” in order to bring together disciplinary power and knowledge (Rabinow, 1991, p. 18), the joining of which Foucault refers to as 'technologies' that "come together around the objectification of the body” (Rabinow, 1991, p. 17). The strength of this panoptic arrangement and disciplinary power emerges from normalising judgement and plays a fundamental role in normalising and correcting 'anomalies' of the overweight or obese body.

A wealth of literature has applied Foucault's concept of bio-power to emphasise that the adolescent body is particularly vulnerable to dominant discourses around the 
apparent ‘obesity epidemic’ (Gard \& Wright, 2001; Rich, 2011b). Rich (2011b), for example, critically examines the bio-pedagogical strategies of new health imperatives that are ubiquitous in "both the formal and popular pedagogic sites of learning about the health and body” (p. 66) and facilitate the means for young people to self-monitor. This Foucauldian lens is central to our own interpretation of the participants' experiences of digital health within this study.

\section{Digital health and popular pedagogical spaces}

The work of Foucault has been influential in guiding a critical examination of digital health and self-tracking. However, much of academic research around self-tracking technologies has uncritically engaged with these devices as instrumental tools for children's health intervention, particularly within the context of schooling (Nichols, Davis, McCord, Schmidt, \& Slezak, 2009; S. Quraishi \& H. Quraishi, 2012). For example, Cummiskey (2011) highlights the functional integration of technology within the PE curriculum, such as the MapMyRun ${ }^{\circledR}$ app, which allows pupils to calculate and monitor their physical activity levels. Research has also explored the functional use of bodily measurement devices (Nichols et al., 2009) and video games as a form of exercise and track body movement (known as exergaming; Vander Schee \& Boyles, 2010), yet studies rarely critically engage with the ethical implications of these technologies on children's long-term wellbeing.

Increasingly, research from a more critical perspective has examined the popular cultural spaces through which adolescents interact and learn about their own bodies and health outside of education (Millington, 2009; Rich, 2011a). These studies critically engage with the frequently restrictive health discourses inherent in adolescents’ everyday informal spaces that entice individuals to surveil their own bodies. For example, weight loss reality television shows, such as The Biggest Loser®, include bio- 
pedagogical strategies to prompt individuals to "undertake surveillance of their own and others' bodies” (Rich, 2011a, p. 3). Such strategies have extended to more interactive, exergaming technologies. For example, the Nintendo Wii Fit ${ }^{\circledR}$ has been critiqued for encouraging children to reflect on their own body in comparison to the norm "as they undertake their journey towards self-governance and thus 'a better you’” (Ohman, Almqvist, Meckbach, \& Quennerstedt, 2014, p. 202). Wearable health monitoring devices, such as the Nike+ FuelBand ${ }^{\circledR}$ and Fitbit ${ }^{\circledR}$, have further transformed the temporal space through which individuals’ body data is monitored. Rich and Miah (2009) emphasise how weight monitoring technologies facilitate 'prosthetic surveillance' and have renegotiated the corporeal boundaries of individuals' virtual and real bodies. Despite a growing critical analysis of digital health, much of this research engages with artefacts within popular media and consumer culture, and the voices of young individuals interacting with these digital spaces are often absent from these accounts.

\section{Methodology and analysis}

This research was approved by the university's ethics committee, which highlighted we had support from an English state grammar school for girls to hold five focus group meetings with eight girls; three of the girls were aged fourteen and the rest were aged seventeen. The Head of the PE department distributed a poster advert to Sports Leaders, inviting them to assist in a 'Research study - using fitness apps in PE'. We provided an information sheet for parents/ guardians and a 'child-friendly' information sheet for pupils, clearly detailing the girls' roles in the focus groups, confidentiality of the data storage and their rights to withdraw from the research at any time. In the interest of ensuring anonymity, the names of the pupils, teachers and school have been replaced with pseudonyms. Over a five week period, the primary investigator met with the same 
girls for forty minutes during their lunch break, once a week.

Prior to the focus groups, the primary investigator prepared a guide containing open-ended questions that allowed flexibility to adjust to the participants' experiences. Task-orientated activities enabled the girls to actively engage in health and fitness apps of their choosing, after which the researcher facilitated rich discussion of the girls' perspectives of the apps. In comparison to one-to-one interviews, the participant-led tasks facilitated opportunities for the girls to discuss and challenge dominant understandings of health and fitness technologies. Moreover, we are reflexive that the perceptions of the participants in this study are not representative of all adolescents and we maintain the belief that meeting with a smaller sample of the same girls over a period of time enhanced the richness of discussions, than had we conducted focus groups with multiple groups of adolescents.

Our analysis centred on interpreting the adolescent girls’ embodied understandings of health and fitness apps within the discursive context of societal health. Foucault's (1988) work resonates with our attention to the intertwining of discourse, knowledge and power through the girls' understandings of digital health technologies. While a Foucauldian discourse analysis is advantageous in examining language and "the ways in which discourse constructs subjectivity, selfhood and power relations” (Sparkes \& Smith, 2014, pp. 136-137), the focus of our analysis was to guide a more in-depth study of the ways in which the girls embodied and negotiated health discourses inherent in digital health technologies.

Specifically, we adapted Markula and Silk’s (2011) poststructuralist approach for analysing interviews, to explore the patterns and themes emerging through the focus groups. After transcribing the focus group audio data, we firstly inductively searched for and identified themes relevant to our research question and purpose. We then 
followed an analysis of the themes through engaging with the intersections and discrepancies between the themes, in order to produce a concise list of three new themes. Finally, we made connections between these new themes and "power relations, theory and previous literature” (Markula \& Silk, 2011, p. 109). Our discussion of the data in the subsequent chapters is centred on these final three themes.

We mobilise various Foucauldian theoretical concepts to further support our analysis, particularly Foucault's concepts of bio-power and technologies of the self in order to analyse the participants' engagement in digital health technologies as pedagogical and discursive sites. This research departs from understanding health and fitness apps solely as 'technologies of dominance', in order to capture the repressive yet also creative opportunities, uncertainties and contradictions within digital health. Thus, we seek not the contingency of a discourse of 'health' as dominating marginal ones, but an exploration of the girls' negotiation of numerous discourses of health embedded in digital technologies.

\section{The digital, self-tracking adolescent generation}

Our analysis and discussion of the focus group data first turns to the ways in which the adolescent girls reinforced the societal acceptance that engaging in self-tracking technologies was a ubiquitous part of their digital generation. This was evident when the girls agreed with Jessica’s assumption that health and fitness apps are a "useful”, accessible function to all young people:

Jessica: People our age are surrounded by the media and everyone's always on their phone, so [fitness] apps are something useful to have, because obviously you're always going to have your phone on you at this age.

This emphasised the girls' position as 'digital natives', able to incorporate technologies 
into their everyday lives. Although the girls did not reflect upon class issues, it is important to consider the girls’ position as relatively privileged, middle-class individuals. Their assumption that all adolescents are surrounded by technology can perhaps be explained by their status as grammar school pupils; the girls rarely reflected upon individuals beyond their particular social worlds whose differing social, cultural and economic circumstances might limit their use of electronic devices.

Social media was a significant part of the participants' engagement in digital health technologies and this further emphasised the appeal of the interactive fitness devices amongst adolescents. During the focus groups, the girls perceived that individuals were likely to share their progress on health and fitness apps through social media for competitive and motivational reasons and that other individuals could be inspired by functional, healthy behaviour:

Sarah: It [Strava ${ }^{\circledR}$ running and cycling app] links with a lot of social media, so you can post your ride or run on Facebook ${ }^{\circledR}$, so that could motivate other people to do it when they see that you've done it.

Charlotte: ...so therefore there's an element of competition, so you want to try and beat each other.

This reinforced how health and fitness apps can facilitate significant social opportunities through online communities. Marwick’s (2012) understanding of social surveillance as the interpersonal, "positive, supportive social effects” (p. 391) of mutual sharing on social media, is particularly relevant to the girls' discussion. However, the way in which individuals might potentially be exploited or subject to peer pressure through use of social media alongside fitness apps was absent from the girls’ narratives.

Throughout the focus groups, the girls frequently reflected on how other individuals might respond to health and fitness apps, particularly those that were 
disengaged from sport and physical activity, whom they perceived needed increased motivation. This was highlighted in the following discussion:

Sarah: I know some people and they download them, they have folders with their apps in, like fitness apps, but they never use them they just have them.

Researcher: Why do you think they have them?

Jessica: Maybe they want to use them, but they don’t really, they just like to look good...like 'I do sport, I am fit'.

The participants perceived that some girls would conform to techniques of selfmonitoring and regulation through health and fitness related apps to give the impression of being a "fit" individual to their peers. It is important to remember that this group of individuals were Sports Leaders who engaged in regular physical activity for enjoyment and thus, they were cynical of individuals who might pretend to use apps to fit into this 'sporty’ ideal that was valued by the girls. The girls demonstrated a critical awareness that individuals might strive to appear to engage in self-discipline to gain the supportive effects of conforming to an 'ideal' body. This resonates with the discourses around the online trend of 'fitspiration', where individuals share fitness related content designed to “inspire viewers towards a healthier lifestyle by promoting exercise and healthy food”, in order to achieve positive body image (Tiggemann \& Zaccardo, 2015, p. 61).

The girls emphasised that health and fitness apps illustrating the transformation of a body could significantly motivate other individuals to engage in fitness pursuits. This emerged when the girls were encouraged to consider the potential negative consequences of health and fitness apps. The following discussion emphasises how the girls perceived that some app users might be demotivated by solely viewing an athlete model demonstrate fitness workouts, while observing another individual gradually transform their body could be more motivating: 
Millie: Maybe the body image it presents... like on a lot of apps, the people doing it looked like they were athletes already. And maybe they should have more people that look normal.

Jessica: Yeah, they should have people that look more normal and then show their progression, instead of having really fit people with six packs already.

Emma: Yeah, it might be a bit intimidating.

Millie: They might think like “I don't look like that” and then they don't use the app.

Grace: Yeah, if they showed them at gradual stages it would probably be a lot more motivating that just seeing this perfect body that it has at the end.

This transformation discourse and the idea of viewing the 'before and after' image of an individuals’ fitness progress frequently emerges across young people’s popular and social media. Although the girls critiqued the lack of "normal" bodies and preoccupation with the "perfect body" on apps, they reinforced restrictive health discourses inherent in the gradual progression towards an 'ideal'. This highlights the pedagogical nature of individuals’ engagement with digital technologies; through which adolescents can learn how to transform one's body to achieve the 'appropriate' body and become healthy bio-citizens (Wright \& Halse, 2014). It is again important to emphasise that the girls were not entirely self-reflexive and often reflected upon the responses of other individuals, whom they thought lacked the motivation to engage in health and sporting pursuits.

In cases where the girls highlighted how they engaged with health and fitness apps, this was predominantly for the purposes of self-tracking and improving their fitness. According to the girls, running related apps such as MapMyRun ${ }^{\circledR}$, facilitated this self-monitoring:

Sarah: I think it's just to give advice and track how you're doing, like I find that my running app is quite useful because you can remember what you've done so 
you can be like I missed one day but oh, I did that the other day so it’s fine. You can look back at what you have done.

The participants agreed that these types of apps were particularly motivating as they provided tangible proof of their efforts. This emphasised neoliberal discourses around the self-responsibility to track and monitor one's body in order to achieve culturally valued definitions of health (Harwood, 2009). These opportunities for prosthetic surveillance significantly reinforced a 'corporeal' responsibility upon the girls and facilitated new ways to monitor their bodies and fitness. Foucault's conceptualisation of technologies of the self is useful in understanding the girls' engagement with health and fitness apps. Markula (2004) emphasises that this concept signifies a shift from the disciplined individual, to one that engages in "practices of freedom [to] enable a creative transformation of the self" (p. 304). This notion is central to "moving beyond simplistic notions of socialisation to a more complex understanding of how the operation of power works to connect the self with the social” (Wright, O’Flynn, \& Macdonald, 2006, p. 708). Throughout the focus groups it was evident that, through deciding to engage in particular digital health technologies, the girls held the freedom to experience the managing of their bodies along particular social lines, conforming to the moral imperatives associated with being a healthy bio-citizen.

\section{'Healthy' and self-responsible bio-citizens}

During the focus groups, the girls emphasised that the characteristics defining a healthy individual were "Happy - physically and mentally, balanced diet, active, outside, good night's sleep”. References to an illness-free or slender body as representative of health were notably absent. Discourses around the social, emotional and physical dimensions of healthy lifestyles elucidated the girls' hesitations to label a particular slender 'ideal' as healthy. The girls' understandings of health moved beyond the discourse of healthism 
that is frequently emphasised across the everyday practices of schooling (Halse, Honey, \& Boughtwood, 2007) and also the informal spaces of digital health and popular media, whereby slender bodies are often representative of health and fitness.

When given the opportunity to engage in health and fitness apps during the focus groups, the girls criticised apps (such as Nike+ Training Club®) for reducing social interaction and emphasised that the individual nature of apps would be detrimental if implemented in their PE lessons:

Millie: I mean you could do the Nike (Nike+ Training Club®) app circuit in just the gym, you could just follow that, but then you can't really do other sports like Rounders, you can only use it for certain things.

Emma: I think apps are more for your independent use... like in a PE lesson you can't really use it, there would be lack of human interaction and communication with your teacher.

Although the girls emphasised that this holistic social interaction was important within school, they perceived that health and fitness apps could be beneficial for helping individuals focus on improving their health outside of school. For example, the girls were uncritical about the way in which individuals should be accountable for their own health and agreed with Emma's perception that apps reinforced the message that:

Emma: ...individual people are responsible for their own health.

When considering the girls' compliance with dominant health imperatives, it is important to acknowledge the significance of their status as Sports Leaders within a relatively privileged grammar school. Previous research has emphasised that middleclass adolescents comply with dominant health discourses in the pursuit of moral behaviour and a functional body (Wachs \& Chase, 2013). The girls’ perspectives that other individuals are accountable for their own health arguably reinforced the girls' own 
presentation of the self as responsible bio-citizens. This neoliberal discourse around the social responsibility for monitoring one’s individual health dominates contemporary understandings of health and weight. Drawing upon Foucault's (1988) conceptualisation that power and knowledge come together to normalise particular bodily ideals and practices; we can understand that the girls enforced the normalising judgement of health as an individual responsibility upon their own and other individuals' bodies. The power of these health and body discourses circulated through the multiple pedagogical spaces the participants engaged with in their everyday lives. While at times the girls emphasised holistic understandings of health, they also emphasised restrictive definitions of health. It is important to note here, as Lupton (1995) emphasises, that “subjects are never fully governed by discourse nor fully capable of stepping outside discourse” (p. 137).

During the focus groups, discussions emerged around the girls' understandings of the so-called 'obesity epidemic'. When encouraged to consider how apps relate to the health of wider society, the girls reinforced dominant discourses around the importance of being healthy citizens to improve society. The girls perceived that growing levels of obesity are a problem in society and health and fitness apps could serve as a free, accessible method for overweight individuals to take responsibility for their own health. They all agreed this would reduce strain on the National Health Service (NHS):

Emma: In the past few years obesity has become more of an issue, you hear about it a lot more, so I guess apps can make people more aware of size, motivate people more to do exercise because people who were just looking through their phone and see a free app they might try it out and find out they might actually enjoy it and do more exercise.

In particular, Emma emphasised that apps encourage individuals to be "more aware of size”, and therefore apps reinforced the visibility of this discourse around monitoring 
the body to lose weight. Foucault's (1988) concept of bio-power is relevant to understanding how health monitoring apps play a role in normalising and correcting ‘deviances’ such as obesity amongst individuals. Through disciplinary practices, individuals internalise "the control mechanisms through the body discipline" and are thus governed by themselves; their own responsibility to "obtain the healthy look" (Markula, 2001, p. 254). Through Foucault's (1988) notion of the panopticon, we can understand how the participants were subjected to wider societal regimes of the dominant discourse of 'healthy' weight norms and moral panic surrounding the 'obesity epidemic'. Localised in the participants' bodies, the girls emphasised the individual imperative to direct surveillance upon one's own health, such as through engaging with digital technologies, in order to reduce the costs of obesity on the welfare state.

Although the girls conformed to dominant obesity discourses, they were nevertheless critical of the business of app-making to make money on individuals trying to lose weight. When encouraged to consider why apps were made, the girls all agreed with Emma's perception that health and fitness monitoring apps could be perceived as appealing business investments:

Emma: ...it's a popular idea with people because quite a lot of people will want to get fit or lose weight maybe because just society and the media and stuff like that, so I guess it is quite a good way to make money.

This narrative emphasised the commercial marketing of self-monitoring technologies to capitalise on attempts to achieve the healthy bio-citizen 'ideal'. Jutel (2006) posits that the "disease of 'overweight' is a perfect and fertile ground for commercial exploitation" (p. 2275). Moreover, societal beliefs around the 'ideal' body “underpin a multi-billion dollar diet, gym, self-help, television and pharmaceutical approach to weight maintenance” (Jutel, 2006, p. 2275). Although the health of today's youth has been 
argued to be a significant target for this neoliberal exploitation and intervention (Lupton, 2013), this group of female adolescents were critically aware of the commercial business ventures of apps.

\section{The girls' critique: apps promote 'ideal' bodies and remove social interaction}

Throughout the focus group meetings, the participants demonstrated a critical understanding that apps frequently promote slender body shapes as representative of an 'ideal'. The girls perceived that the female bodies presented on the apps, such as Popsugar Active ${ }^{\circledR}$ (an app that allows users to create custom routines and share workouts with friends), were unrealistic and likely to result in demotivating other girls. For example, Zoe suggested:

Zoe: It could put people off if they see these people with perfect bodies that have done it, they'll think that I'm obviously not good enough to do this, maybe, I should do something else different, a bit less intimidating, but then other people would find it quite inspirational, thinking 'oh if I keep going with this then I'll be able to do this'.

The girls were further critical that the models in the apps had often undergone cosmetic surgery or edited their images in order to appear as "perfect”, which they critiqued was impossible to achieve. This group of girls demonstrated the agency to consider how narrow representations of the toned, slender body promoted by the health and fitness apps could be demotivating for some yet function as enabling processes for others. Foucault's (1988) concept of technologies of the self helps us understand the creative reconstruction of the body through practices of freedom that help to monitor and transform one's bodies in line with the social norm. This is significant when considering how the adolescent girls had the freedom to either resist or comply with health imperatives. According to Wright et al. (2006), these differing responses can occur 
"even in cases where they [young people] are aware of social critiques of the work of the media and other agencies in promoting body ideals that are unattainable by most” (p. 708). The girls were conscious and at times critical that, through health and fitness apps, individuals are encouraged to engage in self-monitoring and regulation; or as Foucault (1988) articulates, “a certain number of operations on their own bodies and souls” (p. 15) in the pursuit of a bio-citizen ideal.

The girls were particularly critical of health and fitness apps that used the term 'BMI' (body mass index) to classify individuals as having either a 'normal' or ‘abnormal’ weight. This emerged during a discussion of the Wii Fit ${ }^{\circledR}$ game’s promotion of 'ideal' weight as having stigmatising effects upon individuals:

\footnotetext{
Emma:...because my sister's really muscly, she’s considered a bit overweight, even though she's absolutely not, but because of the weight on the thing, it says your overweight, but you're not.

Millie: Yeah.

Emma: So yeah I guess that could be quite negative.

Millie: It's not very accurate.

Emma: Exactly, it can’t look at you and see what you actually look like.
}

Both girls emphasised that BMI measuring was a generalisable and inaccurate approach for those with additional muscle mass and it was necessary to subjectively evaluate an individual's health. Through Foucault's concepts of self-governance and bio-power, we can understand how exergames, such as the Wii Fit ${ }^{\circledR}$, can become problematic as they assert pressure upon young individuals to regulate their bodies according to normative standards and socially acceptable BMI levels (Ohman et al., 2014). While at times young people might seemingly reinforce dominant discourses of health, Beausoleil (2009) emphasises that “young people’s bodies are not completely regulated by the current socially prescribed health imperative” (p. 94). This resonates with the ways in 
which the girls' reinforcement of restrictive health discourses did not endure throughout every focus group discussion. We, therefore, depart from the view of adolescents as cultural dupes, but rather as individuals able to resist performative ideals of the virtuous bio-citizen. Our analysis of the girls' critique resonates with Foucault's belief that discourse can be created, negotiated and resisted.

The girls also critically reflected upon the potential use of digital health technologies in their PE lessons. They frequently emphasised that they valued the holistic, social interactive nature of PE, as this was often absent in their other classes at school. The girls agreed that the repetitive nature of workout based apps would not be advantageous within the PE curriculum, nor would these technologies appeal to the less athletic pupils:

Grace: I think part of the fact why taking part in sport and fitness is fun is because you have other people around you. I know a lot of my sports are based around making friendships and a lot of people get that out of going to fitness classes, you make new friends and I think that's part of what makes it fun. Whereas with the apps it's quite individual, it's not about social interaction.

Zoe: ...pupils would get very bored very quickly and it wouldn't appeal to the less athletic people.

The girls all agreed that the social and community aspects of sport, such as communication and team-work, were more important than digital devices. Rather than focusing entirely upon their own engagement with apps, the girls also reflected upon other individuals whom they perceived to need motivation to engage in sport. By juxtaposing their own perspectives of apps with other "less athletic" individuals, the participants reinforced their own embodied identities as motivated and 'sporty'. It is, therefore, important to reflect upon this presentation of the self and the girls' status as Sports Leaders in the school; the girls each held the embodied sense of self as a 
confident and 'sporty' role model, and associated socialising and enjoyment with their PE lessons. The girls were embedded in sporting cultures and held the social privilege to engage with health and fitness apps, yet at the same time they confidently rejected these technologies for removing the social aspects of sport they valued. If we had conducted focus groups with a group of adolescent girls who were disengaged from sport, their responses to the social environment of PE would have likely been different. This is particularly salient, as previous research exploring adolescent girls' embodied and social experiences within PE lessons has illustrated that girls often feel selfconscious, unhappy and uncomfortable within PE classes (Knowles, Niven, \& Fawkner, 2014).

Digital health technologies have been considered as individual, motivational devices to encourage young people to participate in sport and physical activity (Lupton, 2013). Yet this group of female adolescents critiqued the isolating focus on toning one's body emphasised by devices, as this would be detrimental to their long-term engagement in sport. This final section has illustrated the girls' adoption of alternative discourses to critique health and fitness apps for; the loss of sociality, unrealistic classifications of 'normal' BMI and assumption that apps can help individuals achieve an 'ideal body’. As Millie claimed, “you can’t really define a normal ideal weight, obviously people have different perceptions of what it is”.

\section{Conclusion}

This paper is a response to the need for in-depth analysis of individuals' "subjectivities and embodiment in the world of m-health” (Lupton, 2012, p. 241). When faced with the task of examining the degree to which health and fitness apps are about health or about controlling the body, this research has engaged with the nuances, resistances and contradictions around the multiple meanings of health within our digital society. The 
findings reveal it is imperative to move not only beyond considerations of adolescents as docile, cultural dupes, but also beyond the totalising effects of pedagogical, digital spaces. Indeed, the participant-led innovative and interactive tasks were central to providing the girls with opportunities to express critical understandings of unrealistic ideals of slenderness as representative of health.

Guided by Foucault’s conceptualisations of discourse, bio-power and technologies of self, we have examined the adolescent girls' negotiation of the ambiguities surrounding neoliberal health discourses that manifested affectively and relationally through the self-monitoring technologies. At times during the focus group meetings, the girls reinforced restrictive understandings of health as a responsibility of individuals. They illustrated how, through promoting the imperative to be accountable for one's health, health and fitness apps could encourage citizens to be more healthy and simultaneously help combat the so-called 'obesity epidemic'. Moreover, the girls' engagement in social media alongside health and fitness apps resonated with the online social media trend of 'fitspiration', whereby individuals are inspired to engage in an active lifestyle through sharing a commitment to functional exercise and healthy food (Tiggemann \& Zaccardo, 2015). The girls' narratives around the 'before and after' image as being a fitness motivation emphasised how social and popular media spaces can promote narrow ideals of slenderness and, when used alongside health and fitness apps, reinforce the 'corporeal' responsibility upon adolescents to direct surveillance onto their own bodies.

It is important to acknowledge that these English adolescent girls also understood critical and holistic notions of health, whilst emphasised the potential negative implications of engaging with health and fitness apps. They were particularly critical that health and fitness apps, similar to popular media, promoted a slim, 'ideal' 
body that is unobtainable for most. The girls were further critical of apps and other digital gaming technologies for using limiting measures of BMI to label a 'normal' body. According to Lupton (2013), instead of empowering individuals, digital health technologies increase the visibility of one's health, which can be perceived as a burden and create greater anxiety amongst individuals. Moreover, the girls articulated that digital technologies and social media disregard how individuals feel and should instead accept a diversity of body sizes as representative of health.

The girls all agreed that social interaction through physical activity and sport was important to them. They simultaneously critiqued the individual nature of apps for isolating individuals and removing the holistic characteristics of healthy lifestyles they valued; being active in a fun environment, socialising and competing with friends. This appreciation for the community nature of sport engagement is highly significant. As digitised health promotion is increasingly considered to combat physical activity dropout rates for young individuals (Lupton, 2013), it is imperative to acknowledge the subjectivities of adolescents and what is valued within their everyday lives. Therefore, it is important to acknowledge how this group of adolescent girls perceived health and fitness apps would isolate adolescents and could be detrimental to their long-term engagement in physical activity. Future in-depth research around digitised health promotion may involve examining both pupils’ and PE teachers’ perspectives of the implications of technology upon traditional social interaction within PE.

Throughout this paper we have emphasised it is important to consider the influence of the girls' status as Sports Leaders, embedded within a sporting culture at a relatively privileged grammar school in the UK. While the girls themselves did not reflect upon their class or their engagement in health and fitness apps in 'classed' terms, we have engaged in the nuances of dominant health imperatives within the girls’ 
particular social worlds. This reflexive engagement is central to emphasising that the perspectives within this study were not representative of all adolescent girls. We also need to be mindful that adolescent boys can be equally vulnerable to pressures to conform to societal bodily values as their female peers (Grogan, 2007). Further research needs to engage with the perspectives of both male and female adolescents from different social, economic and cultural backgrounds, in order to facilitate a better understanding of the role of digital health technologies in the lives of various young individuals.

Finally, it is necessary that health promotion practitioners and academics confront the consequences of these developments, particularly as today’s young digital natives are increasingly interacting with self-monitoring technologies (Millington, 2009). We have raised the possibilities for thinking about how, when given the opportunity through creative tasks, adolescents can engage in critical conversations about health and the body portrayed by health and fitness apps and wider media. Azzarito (2010) highlights that "Schools might function as critical sites of resistance to and transformation of contemporary dominant discourses about the female body” (p. 270). Furthermore, it is imperative that public health, schools and future social scientific research considers individuals’ affective and subjective responses to digital health technologies that are highly significant to their level of sustained engagement in physical activity. This study has illustrated how digital health technologies can provide possibilities for young individuals' health promotion, yet careful considerations for how the concept of 'health' is represented are necessary. 


\section{References}

Azzarito, L. (2010). Future girls, transcendent femininities and new pedagogies: Toward girls' hybrid bodies? Sport, Education and Society, 15, 261-275. doi:10.1080/13573322.2010.493307

Beausoleil, N. (2009). An impossible task?: Preventing disordered eating in the context of the current obesity panic. In J. Wright \& V. Harwood (Eds.), Governing bodies: Biopolitics and the "obesity epidemic" (pp. 93-107). London: Routledge.

Cummiskey, M. (2011). There's an app for that: Smartphone use in health and physical education. The Journal of Physical Education, Recreation \& Dance, 82, 24-30. doi:10.1080/07303084.2011.10598672

Evans, J., Rich, E., \& Holroyd, R. (2004). Disordered eating and disordered schooling: What schools do to middle class girls. British Journal of Sociology of Education, 25, 123-142. doi:10.1080/0142569042000205154

Foucault, M. (1978). The history of sexuality, volume 1: An introduction. (R. Hurley, Trans.). New York: Random House.

Foucault, M. (1984). The politics of health in the eighteenth century. In P. Rabinow (Ed.), The Foucault Reader (pp. 273-289). New York: Pantheon Books.

Foucault, M. (1988). Discipline and punish: The birth of the prison. London: Penguin.

Gard, M., \& Wright, J. (2001). Obesity discourses and physical education in a risk society. Studies in Philosophy and Education, 20, 535-549. doi:10.1023/A:1012238617836

Grogan, S. (2007). Body image: Understanding body dissatisfaction in men, women and children. New York: Routledge.

Guillemin, M., \& Gillam, L. (2004). Ethics, reflexivity, and “ethically important moments” in research. Qualitative Inquiry, 10, 261-280. doi:10.1177/1077800403262360

Halse, C., Honey, A., \& Boughtwood, D. (2007). The paradox of virtue: (Re)thinking deviance, anorexia and schooling. Gender and Education, 19, 219-235. doi:10.1080/09540250601166068

Harwood, V. (2009). Theorizing biopedagogies. In J. Wright \& V. Harwood (Eds.), Governing bodies: Biopolitics and the "obesity epidemic" (pp. 15-30). London: Routledge. 
Jutel, A. (2006). The emergence of overweight as a disease entity: Measuring up normality. Social Science and Medicine, 63, 2268-2276. doi:10.1016/j.socscimed.2006.05.028

Knowles, A. M., Niven, A., \& Fawkner, S. (2014). 'Once upon a time I used to be active'. Adopting a narrative approach to understanding physical activity behaviour in adolescent girls. Qualitative Research in Sport, Exercise and Health, 6, 62-76. doi:10.1080/2159676X.2013.766816

Lupton, D. (1995). The imperative of health: Public health and the regulated body. Sage: London.

Lupton, D. (2012). M-Health and health promotion: The digital cyborg and surveillance society. Social Theory \& Health, 10, 229-244. doi:10.1057/sth.2012.6

Lupton, D. (2013). Quantifying the body: Monitoring and measuring health in the age of mHealth technologies. Critical Public Health, 23, 393-403. doi:10.1080/09581596.2013.794931

Lupton, D. (2015). Health promotion in the digital era: A critical commentary. Health Promotion International, 30 (1), 174-183. doi:10.1093/heapro/dau091

Markula, P. (2001). Firm but shapely, fit but sexy, strong but thin: The postmodern aerobicizing female bodies. In A. Yiannakis \& M. J. Melnick (Eds.). Contemporary issues in sociology of sport (pp. 237-360). Champaign, US: Human Kinetics.

Markula, P. (2004). "Tuning into oneself:" Foucault's technologies of the self and mindful fitness. Sociology of Sport Journal, 21, 302-321. Retrieved from http://web.b.ebscohost.com/ehost/pdfviewer/pdfviewer?sid=03c8355c-bddc497c-b64d-46f043c5c8ce\%40sessionmgr120\&vid=2\&hid=128

Markula, P. \& Silk, M. (2011). Qualitative research for physical culture. New York: Palgrave Macmillan.

Marwick, A. E. (2012). The public domain: Social surveillance in everyday life. Surveillance \& Society, 9, 378-393. Retrieved from http://library.queensu.ca/ojs/index.php/surveillance-andsociety/article/view/pub_dom

McEvilly, N., Atencio, M., Verheul, M., \& Jess, M. (2013). Understanding the rationale for preschool physical education: Implications for practitioners' and children's embodied practices and subjectivity formation. Sport, Education and Society, 18, 731-748. doi:10.1080/13573322.2011.606807 
Millington, B. (2009). Wii has never been modern: 'Active video’ games and the 'conduct of conduct'. New Media \& Society, 11, 621-640. doi:10.1177/1461444809102966

Nichols, R., Davis, K. L., McCord, T., Schmidt, D., \& Slezak, A. M. (2009). The use of heart rate monitors in physical education. Strategies: A Journal for Physical and Sport Educators, 22, 19-23. doi:10.1080/08924562.2009.10590845

Ofcom (2011, August 4). A nation addicted to smartphones. Ofcom report. Retrieved from http://media.ofcom.org.uk/news/2011/a-nation-addicted-to-smartphones/

Ohman, M., Almqvist, J., Meckbach, J., \& Quennerstedt, M. (2014). Competing for ideal bodies: a study of exergames used as teaching aids in schools. Critical Public Health, 24, 196-209. doi:10.1080/09581596.2013.872771

Quraishi, S., \& Quraishi, H. (2012). Freedom HIV/AIDS: Mobile phone games for health communication and behaviour change. In J. Donner \& P. Mechael (Eds.), mHealth in Practice: Mobile technology for health promotion in the developing world (pp. 146-61). London: Bloomsbury Publishing Plc.

Rabinow, P. (1991). The Foucault reader. London: Penguin.

Rich, E. (2011a). 'I see her being obesed!’: Public pedagogy, reality media and the obesity crisis. Health, 15, 3-21. doi:10.1177/1363459309358127

Rich, E. (2011b). Exploring the relationship between pedagogy and physical cultural studies: The case of new health imperatives in schools. Sociology of Sport Journal, 28(1), 64-84. Retrieved from http://journals.humankinetics.com/ssjback-issues/ssj-volume-28-issue-1-march/exploring-the-relationship-betweenpedagogy-and-physical-cultural-studies-the-case-of-new-health-imperatives-inschools

Rich, E., \& Miah, A. (2009). Prosthetic surveillance: The medical governance of healthy bodies in cyberspace. Surveillance \& Society, 6, 163-77. Retrieved from http://queens.scholarsportal.info/ojs/index.php/surveillance-andsociety/article/view/3256

Rich, E., \& Miah, A. (2014). Understanding digital health as public pedagogy: A critical framework. Societies, 4, 296-315. doi:103390/soc4020296

Sparkes, A. C., \& Smith, B. (2014). Qualitative research methods in sport, exercise and health: From process to product. Oxon: Routledge.

Sport England (2015). Active design. Planning for health and wellbeing through sport and physical activity. Retrieved from 
https://www.sportengland.org/media/1036460/spe003-active-design-publishedoctober-2015-high-quality-for-web-2.pdf

Tiggemann, M., \& Zaccardo, M. (2015). “Exercise to be fit, not skinny”: The effect of fitspiration imagery on women's body image. Body Image, 15, 61-67. doi:10.1016/j.bodyim.2015.06.003

Vander Schee, C. J., \& Boyles. D. (2010). 'Exergaming', corporate interests and the crisis discourse of childhood obesity. Sport, Education and Society, 15, 169185. doi:10.1080/13573321003683828

Wachs, F. L., \& Chase, L.F. (2013). Explaining the failure of an obesity intervention: Combining Bourdieu's symbolic violence and the Foucault's microphysics of power to reconsider state interventions. Sociology of Sport Journal, 30, 111131. Retrieved from:

http://www.fitnessforlife.org/AcuCustom/Sitename/Documents/DocumentItem/ 01_wachs_SSJ_20120047_111-131-ej.pdf

Wright, J., \& Halse, C. (2014). The healthy child citizen: Biopedagogies and web-based health promotion. British Journal of Sociology of Education, 35, 837-855. doi:10.1080/01425692.2013.800446

Wright, J., O’Flynn, G., \& Macdonald, D. (2006). Being fit and looking healthy: young women's and men's constructions of health and fitness. Sex Roles, 54, 707-716. doi:10.1007/s11199-006-9036-9 